\title{
Association Between Social Participation and Physical Disability Among the Elderly in China: a Longitudinal Fixed-effects Analysis
}

Yanbing Zeng

Xiamen University

Shuang Que

Xiamen University

Ya Fang ( $\nabla$ fangya@xmu.edu.cn )

Xiamen University School of Public Health

Research article

Keywords: China, Social participation, Physical disability, The elderly, Fixed-effects model

Posted Date: January 25th, 2021

DOl: https://doi.org/10.21203/rs.3.rs-151893/v1

License: (c) (i) This work is licensed under a Creative Commons Attribution 4.0 International License.

Read Full License 


\section{Abstract}

Background: There are limited data on the causal relationship between social participation and physical disabilities among the elderly $\geq 65$ in China.

Objective: To investigate the associations between the intensity and diversity of social participation and physical disabilities and how these differ between subgroups of gender and educational attainment.

Methods: We analyzed data from the Chinese Longitudinal Healthy Longevity Survey (CLHLS) 20082018, including 9412 observations. Physical disability was measured using the degree of limitations in the activities of daily living (ADLs). Social participation (i.e., housework, outdoor activities, raising domestic animals, playing cards and/or mahjong and so on) was divided into household, leisure, and sociable types. A fixed-effects model was adopted.

Results: The elderly participating in social activities were at lower risk of developing physical disabilities $(\beta=2.692, p<0.001)$. High participation intensity was associated with a reduction in physical disability for the female $(\beta=0.037, p<0.001)$ and illiterate elderly $(\beta=0.036, p<0.001)$. Raising domestic animals in household type was associated with an increase in physical disability among the female $(\beta=-0.200$, $p<0.01)$ and illiterate elderly $(\beta=-0.196, p<0.01)$. Playing cards and/or mahjong in sociable type was associated with a reduction in physical disability among the male elderly $(\beta=0.120, p<0.05)$ and the elderly with primary school education $(\beta=0.130, p<0.05)$.

Conclusion: These associations between the intensity and diversity of social participation and physical disability might be causal in nature. And that associations differed by gender and educational attainment. Not all forms of social participation could benefit physical ability among the elderly, especially for the female and illiterate.

\section{Background}

At present, the aging problem has become a significant challenge worldwide, especially in China. According to the relevant data from the National Bureau of Statistics and the "China Statistical Yearbook (2019)," as of 2018, the number of people > 65 in China has reached 165.58 million, accounting for $11.9 \%$ of the total population. With the deepening of aging, the health status of the elderly population is not optimistic- the total number of physical disabilities among the elderly is increasing rapidly. The data has shown by the end of the 13th Five-Year Plan, i.e., by the end of 2020, that partially disabled and completely disabled elderly would reach 40 million, accounting for $19.5 \%$ of the elderly population, of which 12.4 million are entirely disabled, accounting for $6.05 \%$ of the elderly population. Notably, the elderly living with a disability can impose a heavy burden on individuals, families, and societies. Therefore, it is imperative to identify protective factors to prevent or delay the onset of physical disability among the elderly to secure the sustainability of healthy aging in China. 
Social participation, as a specific as well as an essential component of structural social capital, has been used to refer to the social sharing of personal resources and is related to a person's participation in social activities, such as a relationship with religion, hobbies, volunteers, and political groups. Previous research has established that social participation is associated with various health outcomes among the elderly, including chronic conditions [1], depression [2], cognitive function [3, 4] and self-rated health [5-7]. There are three kinds of plausible explanations for these associations. The first claims that the process of social participation requires physical and intellectual input, which might encourage the elderly to exercise and improve their cognitive abilities. The second claims that the elderly might reintegrate into society after retirement through social participation to obtain social support, relieve loneliness, and improve mental health. The third claims that social participation might promote health information exchange among the elderly and enable individuals to turn to healthier behaviors through forms, such as peer education. Hence, researchers suggest that enhancing social participation of the elderly might significantly improve cognitive ability and psychological health for urban and rural older adults [8], promote adoption of healthier behaviors [9], and generate social benefits by increasing the community contribution from this group [10]. However, few writers have been able to carry out any systematic research into the impact of social participation on the physical disabilities of the elderly, particularly into the intensity and classification of social participation. Furthermore, while some previous studies have uncovered the association between social participation and physical disability, the problem of endogeneity has failed to be addressed due to using cross-sectional data.

The endogenous issue can broadly be defined as explanatory variables correlated with error terms, meaning that statistical inference results from such research might be unreliable. Why does this problem arise? There are two main reasons: omitted variables and simultaneity [11]. The former means that the omitted variables impact the explanatory and explained variables existing in the model. Generally speaking, it is inevitable to omit explanatory variables because there are still some unknown variables in reality, and no one can find all the variables that can affect the explained variables. The latter refers to reverse causality, i.e., the explained variable can affect the explanatory variable in turn. For instance, if the elderly were disabled, they would not be able to participate in social activities, while the elderly in good health status are more inclined to social participation [12]. Hence, more comprehensive insights are necessary to investigate the complexity of underlying mechanisms between social participation and physical disability. Two of the best methods for addressing this issue are instrumental variable analysis and fixed-effects analysis [13]. Since the instrumental variable method's prerequisites, i.e., identifying variables highly correlated with endogenous explanatory variables and not correlated with random interference items [14], are difficult to meet, the other one was selected in this study.

Therefore, this study aimed to provide more reliable information on the association between social participation and physical disabilities by addressing endogeneity as much as possible. To achieve this aim, a longitudinal study was conducted using data from four waves $(2008,2011,2014$, and 2018$)$ of the Chinese Longitudinal Healthy Longevity Survey (CLHLS). The main variables were social participation and physical disabilities of the elderly in China. Here, social participation was measured using several different outcomes, including the intensity and diversity of participation. Physical disability evaluation 
was performed by the scale of activities of daily living (ADLs). Before the analysis, an F test, Breusch and Pagan Lagrange multiplier (LM) test, and Hausman test were performed to determine whether the fixedeffects model applied to this study or not. A series of models were then developed by considering the interference of some confounding factors, such as sociodemographic characteristics, socioeconomic status, and lifestyle factors. Strong negative associations were found between participating in social activities, household participation type and physical disability. Furthermore, we focused on whether the association between social participation and physical disabilities differed in men and women and educational attainment. Some interesting findings were identified: high participation intensity was only associated with a reduction in physical disability among the female and illiterate elderly; raising domestic animals in the household participation might increase the risk of physical disability among the female and illiterate elderly; playing cards and/or mahjong was associated with a reduction in physical disability among the male elderly and the elderly with primary school education.

To our knowledge, this study is one of the few studies to explore the association between the intensity and diversity of social participation and physical disabilities. It is crucial to conduct such a study to better understand how social participation might protect against the onset of physical disability among the elderly over time. In this study, a fixed-effects model was adopted to a large, nationally representative longitudinal dataset with better validity and precision, allowing us to identify the possibility that social participation has a causal effect on physical disabilities among the elderly in a more comprehensive way. The fixed-effects model can fully control time-invariant confounders that can help address unobserved heterogeneity and reduce the potential effects. Thus, the findings could provide a reference for refining effective health-related intervention strategies to prevent physical disability among the elderly, especially among the female and illiterate.

\section{Methods}

\section{Samples}

The data came from the waves of the Chinese Longitudinal Healthy Longevity Survey (CLHLS), collected by the National Institute of Development, Peking University in 2008, 2011, 2014, and 2018. The CLHLS was developed to provide longitudinal information on sociodemographic characteristics, family and social supports, physical and mental health status, cognitive function, health behaviors, and chronic diseases. The target population for the first wave of the CLHLS was the residents of Chinese 22 provinces aged $\geq 80$ in 1998. Since 2002, attempts were made to survey the persons aged $\geq 65$. Approximately 1.156 billion samples were randomly stratified and selected from rural and urban older adults in the provinces surveyed, accounting for about $85 \%$ of the total population in China. Therefore, large-scale national longitudinal survey data could avoid selection bias to a certain extent. Specific information about the study design, contents, general quality assessment, and availability of the CLHLS is reported elsewhere in detail [15]. 
In this study, we analyzed data from waves $5-8$ because we were interested in changes in social participation and disability among elderly Chinese over 10 years and because these waves were the four most recent standard CLHLS data collections. After excluding 391 respondents who were $<65$ years of age, 16,563 participants were interviewed face-to-face at baseline in 2008. Follow-up interviews were then conducted in 2011, 2014, and 2018, and 8286, 5134, and 2353 respondents who survived were surveyed, respectively. For the longitudinal analysis, we analyzed data from four waves of data collection, which is a perfectly balanced panel dataset (9412 person*year observations).

Ethics approval for the CLHLS project was granted by the Institutional Review Board (IRB) of the Health System of Duke University. All the participants provided written informed consent.

\section{Measures}

The outcome variable, physical disability, was measured using the activities of daily living (ADLs) scale with six basic activities. The respondents were asked: 'For at least the last six months, have you been limited in activities people usually do because of a health problem?' This referred to bathing, dressing, using the toilet, indoor transfer, continence, and eating. We recoded each activity reversely as $1=$ strongly limited, $2=$ limited, and $3=$ not limited. Each activity's values were then added to calculate the total ADLs for each person, ranging from 6 to 18. The larger the value, the better the ADLs among the elderly, indicating a lower probability to suffer from a physical disability.

The independent variable was social participation. To measure social participation, the respondents were asked: 'Do you now perform the following activities regularly?', including housework (cooking, taking care of kids), outdoor activities, garden work, reading newspapers/books, raising domestic animals, playing cards and/or mahjong, watching TV and/or listening to the radio, and social activities (organized). Based on the Likert scale, the responses were recorded reversely as $0=$ never, $1=$ sometimes, $2=$ at least once a month, $3=$ at least once a week, and $4=$ almost every day. We calculated the sum of eight activities for the participants. The values ranged from 0 to 32, where 0 represented total inactivity. Consequently, one dichotomous variable indicating whether or not respondents participated in social activities $(0=$ no, $1=$ yes) was generated.

Furthermore, the total score indicates the intensity of social participation, and the two are in a positive relationship. Given the social context for the social participation among the elderly in China and the data limitation, social participation was analyzed by different types, such as household, leisure, and sociable types [16]. The household type included engaging in housework (cooking, taking care of children) and raising domestic animals; the leisure type included participating in personal outdoor activities, garden work, reading newspapers/books, and watching TV and/or listening to the radio; the sociable type included activities such as playing cards and/or mahjong and participating in organized social activities. As long as one response was not "never" in the above activities, this type of social participation was coded as $1=$ yes $(0=$ no). Additionally, to further analyze the association between specific social participation dimensions and physical disability among the elderly, the answers to the eight questions were recorded as a binary variable. 
The control variables for the analysis were classified into three groups, as follows. The first was sociodemographic variables, such as age, gender (male and female), residence (rural and urban), marital status (dichotomized: not married, i.e., divorced, widowed, or never married; and married), and living arrangement (categorical: living with the family, living alone, living in a nursing home). Age was stratified into three categories: $65-74,75-84$, and $\geq 85$. The second included socioeconomic status, which was measured by educational attainment and self-rated economic conditions. Educational attainment was analyzed as a categorical variable consisting of illiterate, primary school graduate, i.e., attending school for six years, and junior high school and higher education. Self-rated economic status was categorized as poor, fair, and good. The third consisted of lifestyles like smoking and drinking dichotomized into no and yes according to their current lifestyle status. In the fixed-effects models, we excluded time-invariant factors, such as gender and educational attainment, because these variables' potential confounding effects are presumably omitted.

\section{Statistics}

Descriptive statistics calculated for all the variables were presented for the final sample and four waves. The continuous variables were reported as means $(\overline{\mathrm{x}})$ and standard deviations (SD), and dichotomous and categorical variables were reported as percentages. Before using the fixed-effects model, first, three types of linear probability models were estimated for the panel data: (1) the pooled cross-sectional model, (2) the fixed-effects model, (3) the random-effects model. Here, the linear ordinary least regression (OLS) was adopted because the dependent variable in this study was continuous. Then, the F test of constraints, Breusch and Pagan Lagrange multiplier (LM) test, and Hausman test were performed to investigate whether the fixed-effects model was appropriate for this study. The $F$ test is a test of the null hypothesis, where all intercept terms of the model are the same for different individuals. If the $\mathrm{F}$ test is significant, the fixed-effects model is used instead of the pooled OLS model. The LM test is a test for individual-specific effects. If the LM test is significant, the random-effects model is used instead of the pooled OLS model. The Hausman test tests whether there is a significant difference between the fixedand the random-effects estimators. If the Hausman test is significant, it is more appropriate to use the fixed-effects model.

Next, a set of models was developed in the fixed-effects regression. In model 1, we only briefly examined the association between social participation from various aspects and physical disability among the Chinese elderly. Considering the interference of some confounding factors, we added sociodemographic characteristics (age, gender, residence, marital status, and living arrangement) into model 2 , socioeconomic status (educational attainment and self-rated economic conditions) into model 3 , and lifestyle factors (smoking, and drinking) into model 4. Moreover, there is a limitation for the fixed-effects model; the association between time-invariant variables and the physical disability cannot be estimated. Thus, we stratified the observations in terms of gender and educational attainment to further estimate the association between specific dimensions of social participation and physical disability among the elderly. Since the same individual's errors in different years generally have autocorrelation that does not meet the assumption of the calculation method of default common standard error, we estimated the coefficients 
using cluster robust standard errors, along with 95\% confidence intervals $(\mathrm{Cl})$, which might be more accurate. The missing data were imputed using the Markov Chain Monte Carlo Simulation (MCMC). Data analyses were performed using Stata 16.0.

\section{Results}

\section{Descriptive analysis}

Table 1 presents descriptive statistics of the sample wave separately. In 2008, the mean score on the ADLs measure was $16.98(S D=2.43)$, and this value remained roughly stable in $2011(\overline{\mathrm{x}}=16.78, \mathrm{SD}=$ 2.65), $2014(\overline{\mathrm{x}}=16.86, \mathrm{SD}=2.59)$, and $2018(\overline{\mathrm{x}}=17.00, \mathrm{SD}=2.45)$. As can be seen, the proportion of the samples reporting participation in social activities increased over time from 2008 (82.68\%) to 2011 (85.29\%) to 2014 (86.31\%) and to 2018 (88.19\%). On average, although the participation intensity declined from 2014 to 2018, it remained high since 2008. Figure 1 provides more intuitive information on changes in the three types of social participation (household, leisure, and sociable) in all the waves. In all four waves, approximately $80 \%$ of the samples selected the leisure participation type, and more than half focused on the household participation type, while the proportion of social participation did not exceed $30 \%$. The changes over time showed that the proportion of leisure participation continuously increased. The proportion of household participation increased from 2008 to 2014 and then started to decrease. A similar pattern was found for the sociable participation type. 
Table 1

Sample characteristics by panel wave

\begin{tabular}{|c|c|c|c|c|}
\hline Variables & 2008 & 2011 & 2014 & 2018 \\
\hline ADLs ( $\overline{\mathrm{x}} \pm S D)$ & $\begin{array}{l}16.98 \pm \\
2.43\end{array}$ & $\begin{array}{l}16.78 \pm \\
2.65\end{array}$ & $\begin{array}{l}16.86 \pm \\
2.59\end{array}$ & $\begin{array}{l}17.00 \pm \\
2.45\end{array}$ \\
\hline $\begin{array}{l}\text { Social participation (ref. no social } \\
\text { participation) }\end{array}$ & 82.68 & 85.29 & 86.31 & 88.19 \\
\hline Participation intensity $((\overline{\mathrm{x}} \pm S D)$ & $8.42 \pm 6.39$ & $9.53 \pm 6.78$ & $\begin{array}{l}10.00 \pm \\
6.83\end{array}$ & $9.37 \pm 6.26$ \\
\hline $\begin{array}{l}\text { Household participation } \\
\text { (ref. no participation) }\end{array}$ & 54.96 & 58.45 & 61.45 & 58.05 \\
\hline $\begin{array}{l}\text { Leisure participation } \\
\text { (ref. no participation) }\end{array}$ & 79.06 & 81.51 & 82.86 & 84.49 \\
\hline $\begin{array}{l}\text { Sociable participation } \\
\text { (ref. no participation) }\end{array}$ & 21.32 & 25.31 & 27.76 & 23.84 \\
\hline \multicolumn{5}{|l|}{ Sociodemographic features } \\
\hline \multicolumn{5}{|l|}{ Age } \\
\hline $65-74$ & 17.54 & 18.96 & 15.06 & 1.36 \\
\hline $75-84$ & 20.26 & 27.61 & 35.29 & 52.74 \\
\hline$\geq 85$ & 62.20 & 53.43 & 49.65 & 45.90 \\
\hline Female (ref. male) & 57.81 & 54.94 & 53.78 & 54.02 \\
\hline Residence (ref. rural) & 39.73 & 53.03 & 53.33 & 56.74 \\
\hline $\begin{array}{l}\text { Marital status } \\
\text { (ref. not married) } \\
\text { Living arrangement }\end{array}$ & 31.34 & 37.70 & 40.69 & 41.95 \\
\hline Living with family & 82.77 & 81.15 & 80.00 & 78.96 \\
\hline Living alone & 15.37 & 16.63 & 18.06 & 18.61 \\
\hline Living in a nursing home & 1.86 & 2.22 & 1.95 & 2.42 \\
\hline \multicolumn{5}{|l|}{ Socioeconomic status } \\
\hline \multicolumn{5}{|l|}{ Educational attainment } \\
\hline Illiterate & 63.39 & 57.31 & 53.93 & 48.19 \\
\hline
\end{tabular}




\begin{tabular}{|lcccc|}
\hline Variables & $\mathbf{2 0 0 8}$ & $\mathbf{2 0 1 1}$ & $\mathbf{2 0 1 4}$ & $\mathbf{2 0 1 8}$ \\
\hline Primary school education & 27.16 & 31.39 & 33.81 & 36.76 \\
\hline Junior high school and higher education & 9.45 & 11.30 & 12.25 & 15.04 \\
\hline Self-rated economic status & 18.28 & 16.34 & 12.58 & 10.16 \\
Poor & & & & \\
\hline Fair & 68.48 & 66.29 & 70.67 & 68.51 \\
\hline Good & 13.23 & 17.37 & 16.75 & 21.33 \\
\hline Lifestyles & & & & \\
\hline Smoking (ref. not smoking) & 17.01 & 17.99 & 17.28 & 15.68 \\
\hline Drinking (ref. not drinking) & 16.83 & 17.05 & 15.68 & 14.32 \\
\hline $\mathrm{N}$ & 16563 & 8286 & 5134 & 2353 \\
\hline
\end{tabular}

Figure 2 presents changes in ADLs in all the waves for each age group. Overall, there was a clear trend in ADLs' scores, where the mean score of ADLs decreased with aging. It was apparent that from the 65-74 to the 75-84 age group, personal ADLs slowly decreased, while from the 75-84 to $\geq 85$ age group, the descending curve was steeper, with a greater decrease rate. Furthermore, the change curves almost overlapped in 2011 and 2014, while it was different in 2008 and 2018. However, the mean scores of ADLs for each age group did not decrease in all the waves. In the 65-74 age group, the ADLs value was the highest in 2018, and in the other two age groups, this value was just lower than that of in 2008 . This situation might have been caused by selective panel attrition. It seems that the elderly with better ADLs tended to stay in the panel.

\section{The fixed-effects model analysis}

To investigate whether the fixed-effects model was appropriate for this study, we conducted corresponding tests. According to the $F$ test, the null hypothesis could be firmly rejected $(p<0.0001)$, indicating that the fixed-effects model was better than the pooled OLS model. Next, we identified whether it was significant to control for individual random effects. The LM test results $(p<0.0001)$ indicated that the random-effects model should be adopted instead of the pooled OLS model. Third, the Hausman test did not support the null hypothesis $(p<0.0001)$, suggesting that the fixed-effects model was more appropriate for this study.

Table 2 summarizes the estimated association between social participation and physical disability (ADLs) obtained from the fixed-effects model during the 10-year follow-up. In model 1, there was a strong and direct relationship between social participation and physical disability. Compared to when the elderly did not participate in social activities, an increase in "social participation" was associated with 
approximately a 2.692-point improvement in $A D L s(95 \% \mathrm{Cl}=2.268-3.116, \mathrm{p}<0.001)$. Among the elderly with high participation, there was a 0.027-point minimal increase in $A D L s(95 \% \mathrm{Cl}=0.020-0.034, \mathrm{p}<$ 0.001). The Model 1 also shows that, compared to the elderly with household participation, there was a 0.435 -point increase in ADLs than without participation $(95 \% \mathrm{Cl}=0.325-0.545, \mathrm{p}<0.001)$. The results were similar after adjusting for sociodemographic characteristics (model 2), socioeconomic status (model 3), lifestyle factors (model 4). The coefficients of social participation, participation intensity, and household participation decreased slightly; therefore, they could be ignored, suggesting that the confounding effects were mostly limited. In summary, the elderly participating in social activities, with a higher level of participation and household participation, were positively associated with the ADLs, with a lower probability for physical disability. It should also be noted that no significant differences were found between leisure and sociable participation and ADLs. Furthermore, the ADLs decreased with aging, indicating that the risk of physical disability increased in the elderly. There was a 0.375 -point decline in the ADLs when the elderly in the 65-74 category moved to the $\geq 85$ years category ( $95 \% \mathrm{Cl}=-0.494$ to $-0.256, p<0.001)$. 
Table 2

The estimated association between social participation and physical disability (ADLs) obtained from fixed effects regression models

\begin{tabular}{|c|c|c|c|c|}
\hline & Model 1 & Model 2 & Model 3 & Model 4 \\
\hline \multirow[t]{2}{*}{ Social participation } & $2.692^{\star \star \star}$ & $2.669^{\star \star \star}$ & $2.668^{\star \star \star}$ & $2.666^{\star \star \star}$ \\
\hline & $(2.268,3.116)$ & $(2.249,3.090)$ & $(2.248,3.088)$ & $(2.246,3.086)$ \\
\hline \multirow[t]{2}{*}{ Participation intensity } & $0.027^{\star \star \star}$ & $0.025^{\star * \star}$ & $0.024^{\star * \star}$ & $0.024^{\star \star \star}$ \\
\hline & $(0.020,0.034)$ & $(0.018,0.032)$ & $(0.017,0.031)$ & $(0.017,0.031)$ \\
\hline \multirow[t]{2}{*}{ Household participation } & $0.435^{\star \star \star}$ & $0.348^{\star \star \star}$ & $0.352^{\star \star \star}$ & $0.351^{\star \star \star}$ \\
\hline & $(0.325,0.545)$ & $(0.239,0.457)$ & $(0.243,0.461)$ & $(0.242,0.460)$ \\
\hline \multirow[t]{2}{*}{ Leisure participation } & 0.004 & -0.000 & -0.005 & -0.006 \\
\hline & $(-0.149,0.157)$ & $(-0.152,0.151)$ & $(-0.156,0.147)$ & $(-0.157,0.145)$ \\
\hline \multirow[t]{2}{*}{ Sociable participation } & 0.032 & 0.025 & 0.021 & 0.019 \\
\hline & $(-0.033,0.098)$ & $(-0.040,0.091)$ & $(-0.045,0.086)$ & $(-0.046,0.085)$ \\
\hline \multicolumn{5}{|l|}{ Age (ref. 65-74) } \\
\hline \multirow[t]{2}{*}{$75-84$} & & $-0.087^{\star *}$ & $-0.097^{\star \star \star}$ & $-0.090^{* *}$ \\
\hline & & $(-0.141,-0.032)$ & $(-0.152,-0.042)$ & $(-0.144,-0.036)$ \\
\hline \multirow[t]{2}{*}{$\geq 85$} & & $-0.366^{\star \star \star}$ & $-0.387^{\star \star \star}$ & $-0.375^{\star \star \star}$ \\
\hline & & $(-0.483,-0.249)$ & $(-0.505,-0.268)$ & $(-0.494,-0.256)$ \\
\hline \multirow[t]{2}{*}{ Residence } & & -0.050 & -0.053 & -0.051 \\
\hline & & $(-0.118,0.018)$ & $(-0.120,0.015)$ & $(-0.119,0.016)$ \\
\hline \multirow[t]{2}{*}{ Marital status } & & $0.136^{*}$ & $0.139^{*}$ & $0.138^{*}$ \\
\hline & & $(0.010,0.262)$ & $(0.013,0.265)$ & $(0.012,0.264)$ \\
\hline \multicolumn{5}{|l|}{$\begin{array}{l}\text { Living arrangement } \\
\text { (ref. Living with family) }\end{array}$} \\
\hline \multirow[t]{2}{*}{ Living alone } & & $0.276^{\star \star \star}$ & $0.275^{\star \star \star}$ & $0.273^{\star \star \star}$ \\
\hline & & $(0.164,0.388)$ & $(0.163,0.387)$ & $(0.161,0.385)$ \\
\hline \multirow[t]{2}{*}{ Living in a nursing home } & & -0.786 & -0.791 & -0.791 \\
\hline & & $(-1.661,0.089)$ & $(-1.665,0.083)$ & $(-1.665,0.083)$ \\
\hline
\end{tabular}


Self-rated economic

status

(ref. Poor)

Fair

$0.181^{* *} \quad 0.182^{* \star}$

$(0.062,0.301)$

$(0.063,0.302)$

Good

$0.218^{\star \star} \quad 0.219^{\star \star}$

$(0.075,0.360)$

$(0.076,0.361)$

Smoking

0.080

$(-0.026,0.185)$

Drinking

0.076

$(-0.010,0.163)$

Constant

$14.397^{\star \star \star}$

$14.569^{\star \star \star}$

$14.425^{\star \star \star}$

$14.397^{* \star *}$

$(14.031$

14.764)

(14.189,

14.949)

(14.025,

14.825)

(13.996,

14.797)

$R^{2}$

0.250

0.260

0.262

0.262

$\operatorname{adj.} R^{2}$

0.250

0.259

0.261

0.261

AIC

27735.363

27616.123

27599.505

27597.579

$B I C$

27771.111

27694.770

27692.452

27704.825

N

9412

9412

9412

9412

Table 3 presents the results stratified by gender and educational attainment to further estimate the association between specific dimensions of social participation and physical disability (ADLs).

Participation in social activities was associated with a 2.943-point increase in the ADLs $(95 \% \mathrm{Cl}=2.208-$ $3.678, p<0.001)$ for the male elderly, which was higher than the female elderly, and a 2.767-point increase in the ADLs $(95 \% \mathrm{Cl}=1.795-3.739, \mathrm{p}<0.001)$ for the elderly with primary school education, higher than the elderly who were illiterate. There was no significant association for the male elderly and the elderly with primary school education regarding the participation intensity. However, an increase in participation intensity was associated with a 0.037-point rise in the ADLs $(95 \% \mathrm{Cl}=0.016-0.058, \mathrm{p}<0.001)$ for the female elderly, and a 0.036 -point rise in the ADLs $(95 \% \mathrm{Cl}=0.015-0.057, \mathrm{p}<0.001)$ for the illiterate elderly. Concerning specific dimensions of social participation, doing housework, engaging in outdoor activities, and playing cards and/or mahjong were positively associated with the ADLs, which were 
protective factors for the physical disability among the male elderly and the elderly with primary school education. Similar results of the first two dimensions of social participation could be found among the female elderly and the elderly who were illiterate. Interestingly, raising domestic animals was associated with a 0.200-point decline in the ADLs for the female elderly ( $95 \% \mathrm{Cl}=-0.323$ to $-0.078, \mathrm{p}<0.01$ ), and a 0.196 -point decline $(95 \% \mathrm{Cl}=-0.325$ to $-0.067, \mathrm{p}<0.01)$ for the illiterate elderly. Among the elderly with junior high school and higher education, it only could be found that doing housework was associated with a 0.305-point increase in the ADLs $(95 \% \mathrm{Cl}=0.082-0.529, \mathrm{p}<0.01)$. 
Table 3

The estimated association between social participation and physical disability (ADLs) obtained from fixed effects regression models, stratified by gender and educational attainment

\begin{tabular}{|c|c|c|c|c|c|}
\hline & Male & Female & Illiterate & $\begin{array}{l}\text { Primary } \\
\text { school } \\
\text { education }\end{array}$ & $\begin{array}{l}\text { Junior high school } \\
\text { and higher } \\
\text { education }\end{array}$ \\
\hline \multirow[t]{2}{*}{$\begin{array}{l}\text { Social } \\
\text { participation }\end{array}$} & $2.943^{\star \star \star}$ & $2.352^{\star \star \star}$ & $2.342^{\star \star \star}$ & $2.767^{\star \star \star}$ & -0.327 \\
\hline & $\begin{array}{l}(2.208, \\
3.678)\end{array}$ & $\begin{array}{l}(1.877, \\
2.827)\end{array}$ & $\begin{array}{l}(1.864, \\
2.820)\end{array}$ & $\begin{array}{l}(1.795, \\
3.739)\end{array}$ & $(-2.596,1.942)$ \\
\hline \multirow{2}{*}{$\begin{array}{l}\text { Participation } \\
\text { intensity }\end{array}$} & 0.008 & $0.037^{\star \star \star}$ & $0.036^{\star \star \star}$ & 0.006 & 0.013 \\
\hline & $\begin{array}{l}(-0.004 \\
0.020)\end{array}$ & $\begin{array}{l}(0.016 \\
0.058)\end{array}$ & $\begin{array}{l}(0.015, \\
0.057)\end{array}$ & $\begin{array}{l}(-0.007 \\
0.019)\end{array}$ & $(-0.008,0.035)$ \\
\hline \multirow[t]{2}{*}{ Housework } & $0.168^{\star \star \star}$ & $0.476^{\star \star \star}$ & $0.340^{\star \star \star}$ & $0.267^{\star \star \star}$ & $0.305^{\star \star}$ \\
\hline & $\begin{array}{l}(0.077 \\
0.260)\end{array}$ & $\begin{array}{l}(0.293, \\
0.658)\end{array}$ & $\begin{array}{l}(0.173, \\
0.508)\end{array}$ & $\begin{array}{l}(0.133, \\
0.401)\end{array}$ & $(0.082,0.529)$ \\
\hline \multirow[t]{2}{*}{ Outdoor activities } & $0.171^{\star \star}$ & $0.145^{\star}$ & $0.123^{*}$ & $0.205^{\star \star}$ & 0.182 \\
\hline & $\begin{array}{l}(0.065 \\
0.277)\end{array}$ & $\begin{array}{l}(0.027 \\
0.262)\end{array}$ & $\begin{array}{l}(0.002, \\
0.244)\end{array}$ & $\begin{array}{l}(0.073 \\
0.337)\end{array}$ & $(-0.065,0.428)$ \\
\hline \multirow[t]{2}{*}{ Garden work } & -0.011 & -0.013 & 0.062 & 0.011 & 0.006 \\
\hline & $\begin{array}{l}(-0.091 \\
0.069)\end{array}$ & $\begin{array}{l}(-0.107 \\
0.081)\end{array}$ & $\begin{array}{l}(-0.043 \\
0.167)\end{array}$ & $\begin{array}{l}(-0.072 \\
0.093)\end{array}$ & $(-0.158,0.169)$ \\
\hline \multirow{2}{*}{$\begin{array}{l}\text { Read } \\
\text { newspapers/books }\end{array}$} & 0.073 & 0.057 & -0.043 & 0.035 & 0.158 \\
\hline & $\begin{array}{l}(-0.013 \\
0.160)\end{array}$ & $\begin{array}{l}(-0.107 \\
0.221)\end{array}$ & $\begin{array}{l}(-0.194 \\
0.107)\end{array}$ & $\begin{array}{l}(-0.065 \\
0.136)\end{array}$ & $(-0.088,0.405)$ \\
\hline \multirow[t]{2}{*}{$\begin{array}{l}\text { Raise domestic } \\
\text { animals }\end{array}$} & -0.051 & $-0.200^{\star \star}$ & $-0.196^{\star \star}$ & -0.077 & 0.010 \\
\hline & $\begin{array}{l}(-0.144 \\
0.042)\end{array}$ & $\begin{array}{l}(-0.323 \\
-0.078)\end{array}$ & $\begin{array}{l}(-0.325 \\
-0.067)\end{array}$ & $\begin{array}{l}(-0.176 \\
0.022)\end{array}$ & $(-0.259,0.280)$ \\
\hline \multirow{2}{*}{$\begin{array}{l}\text { Play cards and/or } \\
\text { mahjong }\end{array}$} & $0.120^{\star}$ & 0.004 & 0.001 & $0.130^{\star}$ & 0.174 \\
\hline & $\begin{array}{l}(0.017 \\
0.222)\end{array}$ & $\begin{array}{l}(-0.133 \\
0.142)\end{array}$ & $\begin{array}{l}(-0.138 \\
0.140)\end{array}$ & $\begin{array}{l}(0.026 \\
0.234)\end{array}$ & $(-0.063,0.410)$ \\
\hline \multirow{2}{*}{$\begin{array}{l}\text { Watch TV and/or } \\
\text { listen to radio }\end{array}$} & 0.082 & -0.045 & -0.100 & 0.122 & 0.731 \\
\hline & $\begin{array}{l}(-0.087 \\
0.251)\end{array}$ & $\begin{array}{l}(-0.174 \\
0.085)\end{array}$ & $\begin{array}{l}(-0.236 \\
0.037)\end{array}$ & $\begin{array}{l}(-0.063 \\
0.306)\end{array}$ & $(-0.289,1.751)$ \\
\hline
\end{tabular}




\begin{tabular}{|c|c|c|c|c|c|}
\hline & Male & Female & Illiterate & $\begin{array}{l}\text { Primary } \\
\text { school } \\
\text { education }\end{array}$ & $\begin{array}{l}\text { Junior high school } \\
\text { and higher } \\
\text { education }\end{array}$ \\
\hline \multirow{2}{*}{$\begin{array}{l}\text { Social activities } \\
\text { (organized) }\end{array}$} & -0.016 & -0.064 & -0.047 & -0.006 & -0.032 \\
\hline & $\begin{array}{l}(-0.089 \\
0.056)\end{array}$ & $\begin{array}{l}(-0.182 \\
0.055)\end{array}$ & $\begin{array}{l}(-0.157 \\
0.063)\end{array}$ & $\begin{array}{l}(-0.099 \\
0.087)\end{array}$ & $(-0.152,0.089)$ \\
\hline \multicolumn{6}{|l|}{ Age (ref. 65-74) } \\
\hline \multirow[t]{2}{*}{$75-84$} & $-0.085^{\star}$ & $-0.110^{\star}$ & $-0.199^{\star \star \star}$ & -0.059 & -0.099 \\
\hline & $\begin{array}{l}(-0.154 \\
-0.016)\end{array}$ & $\begin{array}{l}(-0.193 \\
-0.026)\end{array}$ & $\begin{array}{l}(-0.307 \\
-0.091)\end{array}$ & $\begin{array}{l}(-0.132 \\
0.014)\end{array}$ & $(-0.238,0.039)$ \\
\hline \multirow[t]{2}{*}{$\geq 85$} & $-0.311^{\star \star \star}$ & $-0.483^{\star \star \star}$ & $-0.545^{\star \star \star}$ & -0.152 & $-0.388^{*}$ \\
\hline & $\begin{array}{l}(-0.467 \\
-0.154)^{\prime}\end{array}$ & $\begin{array}{l}(-0.656 \\
-0.310)\end{array}$ & $\begin{array}{l}(-0.732 \\
-0.359)\end{array}$ & $\begin{array}{l}(-0.363 \\
0.060)\end{array}$ & $(-0.684,-0.091)$ \\
\hline \multirow[t]{2}{*}{ Residence } & -0.055 & -0.078 & $-0.115^{\star}$ & -0.074 & -0.075 \\
\hline & $\begin{array}{l}(-0.145 \\
0.034)\end{array}$ & $\begin{array}{l}(-0.180 \\
0.024)\end{array}$ & $\begin{array}{l}(-0.221 \\
-0.010)\end{array}$ & $\begin{array}{l}(-0.162 \\
0.015)\end{array}$ & $(-0.270,0.121)$ \\
\hline \multirow[t]{2}{*}{ Marital status } & 0.152 & 0.112 & 0.038 & $0.238^{* *}$ & -0.325 \\
\hline & $\begin{array}{l}(-0.023 \\
0.327)\end{array}$ & $\begin{array}{l}(-0.069 \\
0.292)\end{array}$ & $\begin{array}{l}(-0.137 \\
0.212)\end{array}$ & $\begin{array}{l}(0.062 \\
0.414)\end{array}$ & $(-0.791,0.141)$ \\
\hline \multicolumn{6}{|l|}{$\begin{array}{l}\text { Living } \\
\text { arrangement }\end{array}$} \\
\hline \multicolumn{6}{|l|}{$\begin{array}{l}\text { (ref. Living with } \\
\text { family) }\end{array}$} \\
\hline \multirow[t]{2}{*}{ Living alone } & $0.191^{\star \star}$ & $0.281^{\star \star \star}$ & $0.288^{\star \star \star}$ & $0.216^{\star *}$ & 0.092 \\
\hline & $\begin{array}{l}(0.046 \\
0.337)\end{array}$ & $\begin{array}{l}(0.127 \\
0.435)\end{array}$ & $\begin{array}{l}(0.123 \\
0.452)\end{array}$ & $\begin{array}{l}(0.083 \\
0.349)\end{array}$ & $(-0.308,0.493)$ \\
\hline \multirow{2}{*}{$\begin{array}{l}\text { Living in a nursing } \\
\text { home }\end{array}$} & 0.489 & $-1.813^{\star \star}$ & -0.903 & $-2.050^{*}$ & -0.328 \\
\hline & $\begin{array}{l}(-0.471 \\
1.450)\end{array}$ & $\begin{array}{l}(-3.060 \\
-0.565)\end{array}$ & $\begin{array}{l}(-2.147 \\
0.342)\end{array}$ & $\begin{array}{l}(-4.019 \\
-0.081)\end{array}$ & $(-3.797,3.141)$ \\
\hline \multicolumn{6}{|l|}{$\begin{array}{l}\text { Self-rated } \\
\text { economic status } \\
\text { (ref. Poor) }\end{array}$} \\
\hline Fair & $0.172^{*}$ & $0.187^{\star}$ & $0.209^{*}$ & 0.132 & 0.302 \\
\hline
\end{tabular}




\begin{tabular}{|c|c|c|c|c|c|}
\hline & Male & Female & Illiterate & $\begin{array}{l}\text { Primary } \\
\text { school } \\
\text { education }\end{array}$ & $\begin{array}{l}\text { Junior high school } \\
\text { and higher } \\
\text { education }\end{array}$ \\
\hline & $\begin{array}{l}(0.018, \\
0.327)\end{array}$ & $\begin{array}{l}(0.015, \\
0.359)\end{array}$ & $\begin{array}{l}(0.039 \\
0.380)\end{array}$ & $\begin{array}{l}(-0.032 \\
0.296)\end{array}$ & $(-0.157,0.761)$ \\
\hline \multirow[t]{2}{*}{ Good } & 0.167 & $0.255^{*}$ & $0.342^{\star *}$ & 0.184 & 0.266 \\
\hline & $\begin{array}{l}(-0.019 \\
0.354)\end{array}$ & $\begin{array}{l}(0.049, \\
0.461)\end{array}$ & $\begin{array}{l}(0.133, \\
0.551)\end{array}$ & $\begin{array}{l}(-0.003 \\
0.371)\end{array}$ & $(-0.237,0.769)$ \\
\hline \multirow[t]{2}{*}{ Smoking } & 0.090 & 0.054 & 0.043 & 0.037 & 0.192 \\
\hline & $\begin{array}{l}(-0.023 \\
0.202)\end{array}$ & $\begin{array}{l}(-0.207 \\
0.315)\end{array}$ & $\begin{array}{l}(-0.129 \\
0.215)\end{array}$ & $\begin{array}{l}(-0.126 \\
0.200)\end{array}$ & $(-0.141,0.524)$ \\
\hline \multirow[t]{2}{*}{ Drinking } & 0.093 & 0.089 & 0.056 & 0.050 & 0.144 \\
\hline & $\begin{array}{l}(-0.002 \\
0.188)\end{array}$ & $\begin{array}{l}(-0.086 \\
0.265)\end{array}$ & $\begin{array}{l}(-0.102 \\
0.213)\end{array}$ & $\begin{array}{l}(-0.060 \\
0.160)\end{array}$ & $(-0.126,0.413)$ \\
\hline \multirow[t]{2}{*}{ Constant } & $14.223^{\star \star \star}$ & $14.516^{\star \star \star}$ & $14.854^{\star \star \star}$ & $14.261^{\star \star \star}$ & $16.684^{\star \star \star}$ \\
\hline & $\begin{array}{l}\text { (13.484, } \\
14.963)\end{array}$ & $\begin{array}{l}(14.045 \\
14.988)\end{array}$ & $\begin{array}{l}\text { (14.394, } \\
15.315)\end{array}$ & $\begin{array}{l}(13.265 \\
15.256)\end{array}$ & $(14.297,19.072)$ \\
\hline$R^{2}$ & 0.263 & 0.280 & 0.275 & 0.250 & 0.109 \\
\hline $\operatorname{adj} \cdot R^{2}$ & 0.260 & 0.277 & 0.272 & 0.246 & 0.095 \\
\hline$A I C$ & 11137.259 & 15982.574 & 13701.425 & 7536.526 & 2942.971 \\
\hline$B I C$ & 11264.716 & 16113.251 & 13830.084 & 7659.845 & 3046.327 \\
\hline$N$ & 4328 & 5084 & 4596 & 3519 & 1297 \\
\hline
\end{tabular}

\section{Discussion}

Prior studies noted that social participation matters, especially in an aging population with improved global healthy life expectancy [17-19]. However, few studies have focused on exploring the association between social participation and physical disability among the elderly. It is a universal question whether the observed association represents a causal effect from social participation on physical disability or just reflects a selection effect caused by unobserved (time-invariant) heterogeneity. Therefore, there were two objectives in this study. The first was to investigate the causal relationship between social participation and physical disability, and the second was to analyze methodological issues to improve empirical analysis on this topic. First of all, the F test, LM test, and Hausman test were undertaken to verify whether the fixed-effects model was more appropriate than the other models. Then, we analyzed the association between the intensity and diversity of social participation and physical disability and stratified results by gender and educational attainment. As expected, the results suggested that social participation could 
prevent the onset of physical disability, and there were different associations between various types of social participation and different subgroups, reflecting that it is essential to consider individual heterogeneity when viewing social participation as a public health strategy.

Health status declines as the population ages, with a substantial fall in the most elderly group [20]. In accordance, our findings provided pertinent evidence about the apparent trend of increasing physical disability with age, and it was apparent in the elderly $\geq 85$. Among the elderly, low muscle mass and physical frailty are associated with physical disabilities, and social participation might positively affect the prevention of physical disability [21].

Overall, this analysis showed that the elderly reporting social participation had a strong negative association with physical disabilities, which was generally consistent with Gao et al. [22]. The possible reason might be that the elderly's participation in social activities is a significant priority for preventing physical disability. A high participation intensity could prevent the onset of physical disability to a certain extent by being physiologically and psychologically rewarding. The former indicates that a high level of social participation might maintain physical performance and reduce the functional limitations of the elderly [23]. The latter indicates that a high level of social participation might provide perfect opportunities for the elderly to experience positive social interactions, receive social support, and achieve happiness [24].

Concerning the type of social participation, household participation was associated with low risks of physical disabilities, suggesting that the elderly could develop proactive abilities from activities like cooking and taking care of children. This finding might be explained by the fact that household participation might help the elderly stay physically active, exerting direct health benefits and contributing to better functionality [25]. Moreover, considering the Chinese cultural contexts, caring for grandchildren as a significant aspect of household participation is one opportunity for intergenerational support [26]. This seems beneficial for mobility improvements due to increased physical activity from interacting with grandchildren [27].

At the same time, we should not ignore that this study did not show any significant association between leisure and sociable participation and physical disabilities. That null effect might be caused because some confounding factors and effects of mediators have not been accounted for, which could have influenced the relationship between leisure and sociable participation and physical disabilities. For instance, Aida et al. [28] found that the elderly living in communities with higher mistrust tended to have a higher risk for the onset of physical disability, and Garoon et al. [29] concluded from a qualitative study that neighborhood mistrust might lead to decreased social engagement in once-meaningful social interactions (with institutions or people) in some instances. Such an intermediate variable might lead to underestimating the association between leisure and sociable participation and physical disabilities.

Nevertheless, among the results stratified by gender and educational attainment, we further focused on the different associations between specific dimensions of social participation and physical disability. The results showed that a high participation intensity was only associated with physical disability among the 
female and illiterate elderly. The difference in educational attainment might also be explained from the perspective of gender difference. In China, females typically have lower educational attainment than males. The female elderly might become socially isolated more easily because of household and family responsibilities to report lower functional status levels [30]. Therefore, the participation intensity might have a larger beneficial role among the female elderly than males.

Engaging in outdoor activities that accounts for a large proportion of the leisure participation was associated with better physical function, independently of whether the elderly was male or female, illiterate, or with primary school education. This finding coincides with past research, which suggested that physical activities like aerobic and strengthening exercises were efficient ways to improve individuals' health status [31]. Also, as indicated by Everard et al. [32], maintaining high-demand leisure activities was associated with greater physical health. Particularly, raising domestic animals in household participation might increase the risk of physical disabilities among the female and illiterate elderly. As stated above, the female and illiterate elderly are relatively disadvantaged. Considering the gender division of household labor, the female elderly may be more likely than males to be involved in a higher share of domestic chores (such as cooking, cleaning, and child care) [33]. Raising domestic animals might cause them to be overworked and more vulnerable to physical disabilities.

Moreover, playing cards and/or mahjong, i.e., sociable participation, could decrease the risk of physical disability among the male elderly and the elderly with primary school education. Compared to the female and illiterate elderly, these groups might have more channels to connect with their society and are thus more likely to be protected against social isolation. Moreover, playing cards and/or mahjong, which is one of the most popular social activities that the Chinese elderly engage in, might improve reaction ability and memory to stimulate brain function and emotional health [34], leading to good physical health.

The present study had certain limitations. First, we did not control all the possible time-dependent confounders because of data limitations. Second, social participation and physical disability were based on responses to a self-report questionnaire, which might have resulted in the observed association between social participation and physical disability, overestimating or underestimating it. Third, the attrition bias of the panel data might exist. It seems that the participants with better ADLs tend to stay in the panel, and they are more likely to participate in social activities. Moreover, the results cannot be generalized to non-participants with low physical ability. Further progress will require attention to identifying the underlying mechanisms between social participation and physical disability. It is important to measure social participation and its possible mediatory effect on physical disability as various factors can affect the functional status of the elderly. In addition, we could further estimate the effects of time-invariant factors and explore inter-individual and intra-individual variations by a multilevel model.

Despite these limitations, our findings suggest that social participation has important implications for public health and social policy in an aging society. Public health interventions and initiatives might be able to prevent physical disabilities by developing social participation programs. Early detection and 
interventions to improve health for most elderly individuals with physical disabilities are likely to pay dividends [35]. At the same time, more detailed and differentiated intervention strategies should be formulated, and it should be determined what kinds of social activities are necessary for the elderly, especially for the female and illiterate.

\section{Conclusions}

In conclusion, the present longitudinal study provided more rational and accurate information about the relation between the intensity and diversity of social participation and physical disabilities in 10 years of follow-up, with more differentiated and helpful insights regarding research in this field. Participating in social activities, enhancing social participation, and household participation might limit or delay the onset of physical disabilities among the elderly. However, when we stratified the results by gender and educational attainment, we found an apparently different association between various types of social participation and physical disabilities between different subgroups. This is a crucial implication for developing the Chinese effective health policy, which might complement comprehensive efforts to sustain physical function and promote healthy aging. As one aspect of health-promoting behavior, social participation should be applied as a public health intervention component. Meanwhile, it is critical to encourage social participation in a more differentiated manner by considering gender and educational differences.

\section{Abbreviations}

CLHLS: Chinese Longitudinal Healthy Longevity Survey; ADLs: activities of daily living; LM: Breusch and Pagan Lagrange multiplier; SD: standard deviations; OLS: linear ordinary least regression; Cl: confidence intervals; MCMC: Markov Chain Monte Carlo Simulation.

\section{Declarations}

\section{Ethics approval and consent to participate}

The dataset used in this study is a publicly available dataset. Not applicable.

\section{Consent for publication}

Not applicable.

\section{Availability of data and material}

The CLHLS dataset is publicly available. Information about the data source and available data are found at https://www.icpsr.umich.edu/icpsrweb/DSDR/studies/. Researchers can obtain these data after 


\section{Competing interests}

The authors declare that they have no competing interests.

\section{Funding}

This work was supported by National Natural Science Foundation of China (71874147). The funder had no role in the study design, the collection, analysis and interpretation of the data, the writing of the report, and the decision to submit the article for publication.

\section{Authors' contributions}

Ya Fang conceived and designed the study, supervised the data analysis; Yanbing Zeng and Shuang Que performed all statistical analyses; All authors contributed to manuscript writing and revising. All authors have read and approved the final manuscript.

\section{Acknowledgments}

Data used in this research were provided by the Chinese Longitudinal Healthy Longevity Survey (CLHLS) study, which was managed by the Center for Healthy Ageing and Development Studies, Peking University.

\section{References}

1. Santini ZI, Jose PE, Koyanagi A, Meilstrup C, Nielsen L, Madsen KR, Koushede V: Formal social participation protects physical health through enhanced mental health: A longitudinal mediation analysis using three consecutive waves of the Survey of Health, Ageing and Retirement in Europe (SHARE). SOC SCI MED 2020, 251:112906.

2. Amegbor PM, Braimah JA, Adjaye-Gbewonyo D, Rosenberg MW, Sabel CE: Effect of cognitive and structural social capital on depression among older adults in Ghana: A multilevel cross-sectional analysis. ARCH GERONTOL GERIAT 2020, 89:104045.

3. Glei DA, Landau DA, Goldman N, Chuang Y, Rodríguez G, Weinstein M: Participating in social activities helps preserve cognitive function: an analysis of a longitudinal, population-based study of the elderly. INT J EPIDEMIOL 2005, 34(4):864-871.

4. Biddle KD, D'Oleire Uquillas F, Jacobs HIL, Zide B, Kirn DR, Rentz DM, Johnson KA, Sperling RA, Donovan NJ: Social Engagement and Amyloid- $\beta$-Related Cognitive Decline in Cognitively Normal Older Adults. The American Journal of Geriatric Psychiatry 2019, 27(11):1247-1256. 
5. Nyqvist F, Nygård M, Jakobsson G: Social participation, interpersonal trust, and health: A study of 65and 75-year-olds in western Finland. SCAND J PUBLIC HEALT 2012, 40(5):431-438.

6. Eriksson $\mathrm{M}, \mathrm{Ng} \mathrm{N}$ : Changes in access to structural social capital and its influence on self-rated health over time for middle-aged men and women: A longitudinal study from northern Sweden. SOC SCI MED 2015, 130:250-258.

7. Vogelsang EM: Older adult social participation and its relationship with health: Rural-urban differences. HEALTH PLACE 2016, 42:111-119.

8. Sun J, Lyu S: Social participation and urban-rural disparity in mental health among older adults in China. J AFFECT DISORDERS 2020, 274:399-404.

9. Nieminen T, Prättälä R, Martelin T, Härkänen T, Hyyppä MT, Alanen E, Koskinen S: Social capital, health behaviours and health: a population-based associational study. BMC PUBLIC HEALTH2013, 13(1):613.

10. Douglas $\mathrm{H}$, Georgiou A, Westbrook J: Social participation as an indicator of successful aging: an overview of concepts and their associations with health. AUST HEALTH REV 2017, 41(4):455.

11. Antonakis J, Bendahan S, Jacquart P, Lalive R: On making causal claims: A review and recommendations. The Leadership Quarterly 2010, 21(6):1086-1120.

12. Rowiński R, Morgulec-Adamowicz N, Ogonowska-Slodownik A, Dąbrowski A, Geigle PR: Participation in leisure activities and tourism among older people with and without disabilities in Poland. ARCH GERONTOL GERIAT 2017, 73:82-88.

13. Veenstra G, Vanzella-Yang A: Family income and self-rated health in Canada: Using fixed effects models to control for unobserved confounders and investigate causal temporality. SOC SCI MED 2020, 250:112884.

14. Arezzo MF, Giudici C: The Effect of Social Capital on Health Among European Older Adults: An Instrumental Variable Approach. SOC INDIC RES 2017, 134(1):153-166.

15. Zeng Y: Toward deeper research and better policy for healthy aging - using the unique data of Chinese longitudinal healthy longevity survey. China Economic Journal 2012, 5(2-3):131-149.

16. Jingyan Tan: Social Participation of the Elderly in Rural my country: Analysis Based on CLHLS (2014). Think Tank Era 2020, (09):3-7. (in Chinese)

17. Sirven N, Debrand T: Social participation and healthy ageing: An international comparison using SHARE data. SOC SCI MED 2008, 67(12):2017-2026.

18. Douglas $\mathrm{H}$, Georgiou A, Westbrook J: Social participation as an indicator of successful aging: an overview of concepts and their associations with health. AUST HEALTH REV 2017, 41(4):455.

19. Ang S: Social participation and health over the adult life course: Does the association strengthen with age? SOC SCI MED 2018, 206:51-59.

20. Chatterji S, Byles J, Cutler D, Seeman T, Verdes E: Health, functioning, and disability in older adults-present status and future implications. LANCET 2015, 385(9967):563-575. 
21. Ishii H, Tsutsumimoto K, Doi T, Nakakubo S, Kim M, Kurita S, Shimada H: Effects of comorbid physical frailty and low muscle mass on incident disability in community-dwelling older adults: A 24month follow-up longitudinal study. MATURITAS 2020, 139:57-63.

22. Gao M, Sa Z, Li Y, Zhang W, Tian D, Zhang S, Gu L: Does social participation reduce the risk of functional disability among older adults in China? A survival analysis using the 2005-2011 waves of the CLHLS data. BMC GERIATR 2018, 18(1).

23. Groessl EJ, Kaplan RM, Rejeski WJ, Katula JA, Glynn NW, King AC, Anton SD, Walkup M, Lu C, Reid K et al: Physical Activity and Performance Impact Long-term Quality of Life in Older Adults at Risk for Major Mobility Disability. AM J PREV MED 2019, 56(1):141-146.

24. Kim J, Kim J, Kim Y, Han A, Nguyen MC: The contribution of physical and social activity participation to social support and happiness among people with physical disabilities. DISABIL HEALTH J 2020:100974.

25. Li Y, Xu L, Chi I, Guo P: Participation in Productive Activities and Health Outcomes Among Older Adults in Urban China. The Gerontologist 2014, 54(5):784-796.

26. Ates M: Does grandchild care influence grandparents' self-rated health? Evidence from a fixed effects approach. SOC SCI MED 2017, 190:67-74.

27. Ku LJE, Stearns SC, Van Houtven CH, Lee SYD, Dilworth-Anderson P, Konrad TR: Impact of Caring for Grandchildren on the Health of Grandparents in Taiwan. The Journals of Gerontology Series B: Psychological Sciences and Social Sciences 2013, 68(6):1009-1021.

28. Aida J, Kondo K, Kawachi I, Subramanian SV, Ichida Y, Hirai H, Kondo N, Osaka K, Sheiham A, Tsakos $\mathrm{G}$ et al: Does social capital affect the incidence of functional disability in older Japanese? A prospective population-based cohort study. J EPIDEMIOL COMMUN H2012, 67(1):42-47.

29. Garoon J, Engelman M, Gitlin L, Szanton S: Where does the neighborhood go? Trust, social engagement, and health among older adults in Baltimore City. HEALTH PLACE 2016, 41:58-66.

30. Lee HY, Jang S, Lee S, Cho S, Park E: The relationship between social participation and self-rated health by sex and age: A cross-sectional survey. INT J NURS STUD 2008, 45(7):1042-1054.

31. Guan J, Wang G, Geng C: The Impact of Different Levels of Physical Activity on Health among Middle-Aged and Elderly Chinese Adults. IRAN J PUBLIC HEALTH 2019, 48(11):1971-1978.

32. Everard KM, Lach HW, Fisher EB, Baum MC: Relationship of activity and social support to the functional health of older adults. The journals of gerontology. Series B, Psychological sciences and social sciences 2000, 55(4):S208.

33. Pinillos-Franco S, Kawachi I: The relationship between social capital and self-rated health: A gendered analysis of 17 European countries. SOC SCI MED 2018, 219:30-35.

34. Gao M, Sa Z, Li Y, Zhang W, Tian D, Zhang S, Gu L: Does social participation reduce the risk of functional disability among older adults in China? A survival analysis using the 2005-2011 waves of the CLHLS data. BMC GERIATR 2018, 18(1).

35. Chatterji S, Byles J, Cutler D, Seeman T, Verdes E: Health, functioning, and disability in older adults-present status and future implications. LANCET 2015, 385(9967):563-575. 
Figures

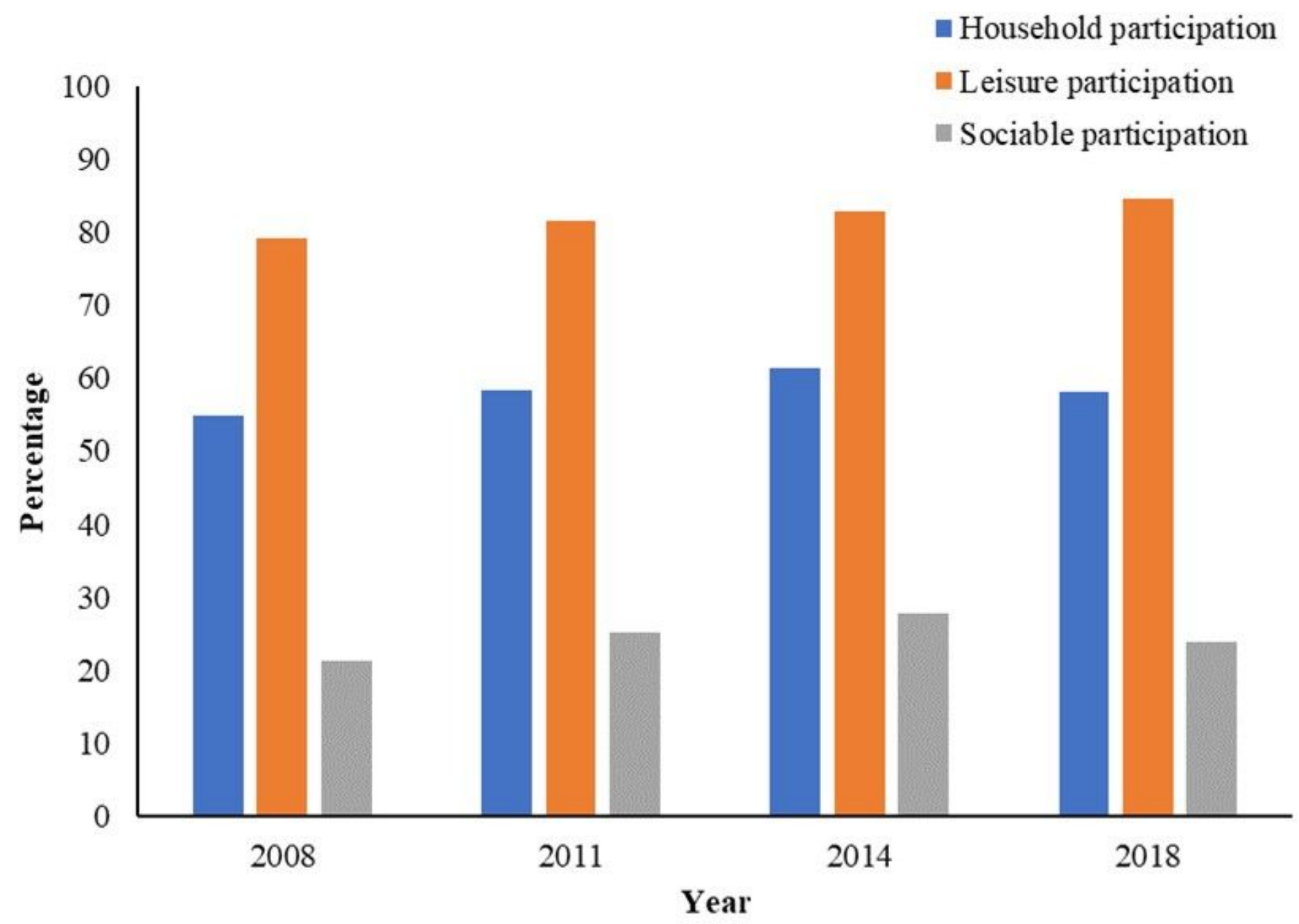

Figure 1

Changes in type of social participation over all waves (percentage) 


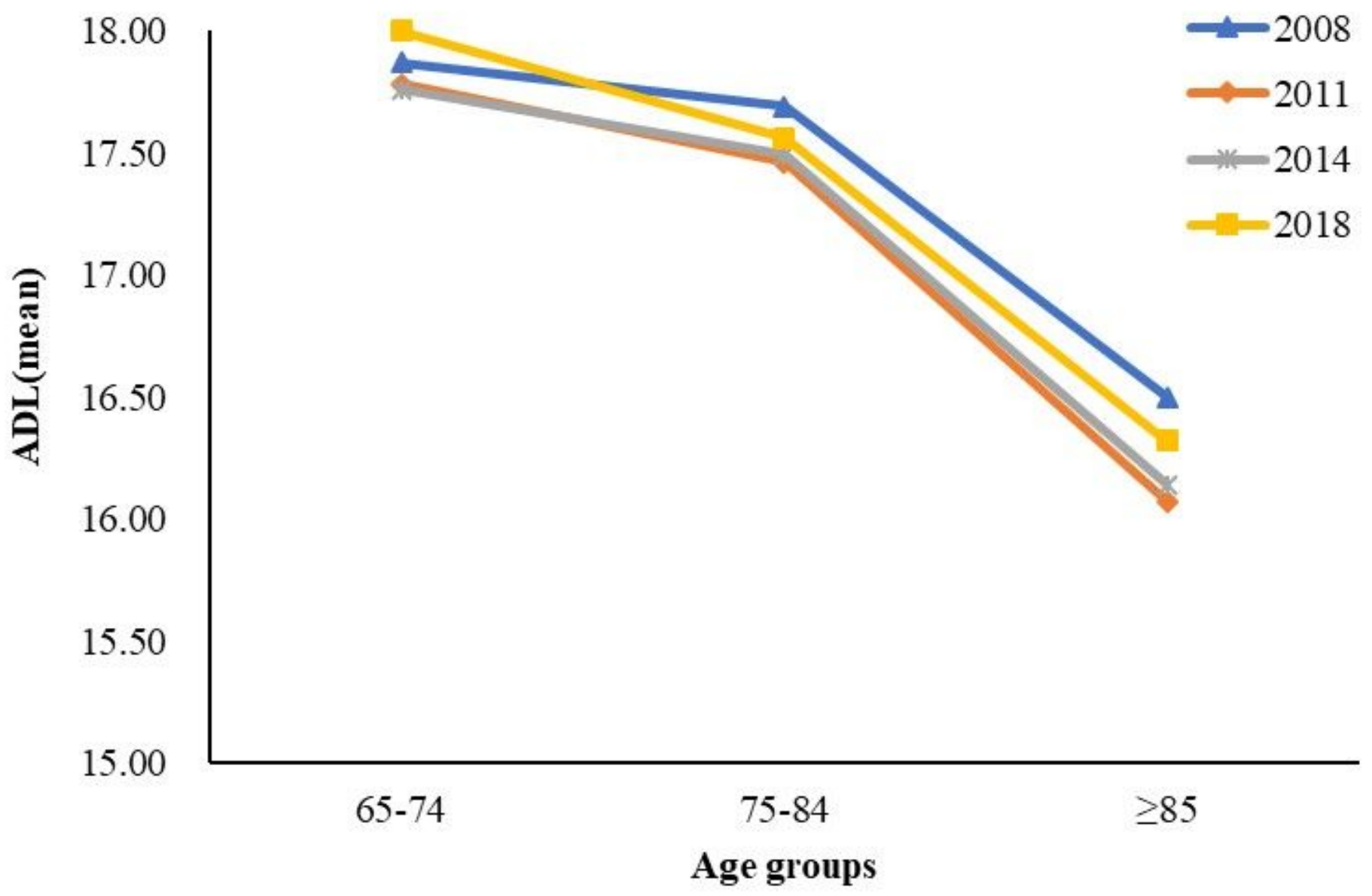

Figure 2

Changes in ADLs over all waves for each age group (mean) 